\title{
Retinitis pigmentosa, metaphyseal chondrodysplasia, and brachydactyly: an affected brother and sister
}

\author{
CALBERT I PHILLIPS,* RUTH WYNNE-DAVIES, † N LESLIE STOKOE, * \\ AND MARJORIE NEWTON \\ From * the Department of Ophthalmology, University of Edinburgh, and Princess Alexandra Eye \\ Pavilion, Royal Infirmary, Edinburgh; $\dagger$ the Department of Orthopaedic Surgery (Clinical Genetics), \\ University of Edinburgh; and $\ddagger$ the MRC Clinical and Population Cytogenetics Research Unit, \\ Western General Hospital, Edinburgh
}

SUMMARY A brother and sister, children of normal parents, are described. They had retinitis $\vec{\circ}$ pigmentosa, causing near-blindness as a result of very narrow fields of vision, associated witho metaphyseal chondrodysplasia and marked shortening of the metacarpals and terminal phalanges. Autosomal recessive inheritance is suggested with a common biochemical cause for all these defects. Th This apparently new association of retinitis pigmentosa with a systemic bone dysplasia emphasises $\frac{\mathbb{O}}{2}$ that this not uncommon clinical diagnosis has a variety of different possible causes.

The association between retinitis pigmentosa and metaphyseal chondrodysplasia has not previously been recorded. The eye disease is known to occur with many other conditions, usually of the nervous system, such as deafness, ${ }^{1}$ and in Refsum syndrome. ${ }^{2}$ Associations with metabolic dyscrasias have also been recorded, such as the Bassen-Kornzweig syndrome ${ }^{3}$ with abetalipoproteinaemia. Coincidence with skeletal disease is uncommon. Krill and Archer ${ }^{4}$ list Paget's disease, osteogenesis imperfecta (Lobstein syndrome), Marfan syndrome, and osteopetrosis 'familiaris', but in the first pure chance was probably the explanation.

\section{Case reports}

The sister was born on 28.4.62. At the age of 22 months she was noted to have very small hands and feet. At 3 years 9 months she developed a divergent squint, for which operation was performed at the age of 6 and again at 9 years. No fundus abnormality was noted then. At the age of $9 \frac{1}{2}$ she was reported to be very clumsy, attributed to the exceptionally small stubby hands (fig 1). An initial diagnosis of achondroplasia was made, but in retrospect the radiological changes suggested a metaphyseal chondrodysplasia (fig 2). Her height was then, and has remained, on the third centile (table). It was not until she was $15 \frac{1}{2}$ years old that difficulty in seeing in the dark was reported and the diagnosis of typical, though ophthalmoscopically mild, retinitis Received for publication 21 March 1980 pigmentosa was made. By 17 years she had a severely $\stackrel{\oplus}{\rightarrow}$ restricted field of vision ( $10^{\circ}$ or less), but apart from this was fit and had no skeletal problems.

Her brother was born on 4.11 .65 and there were

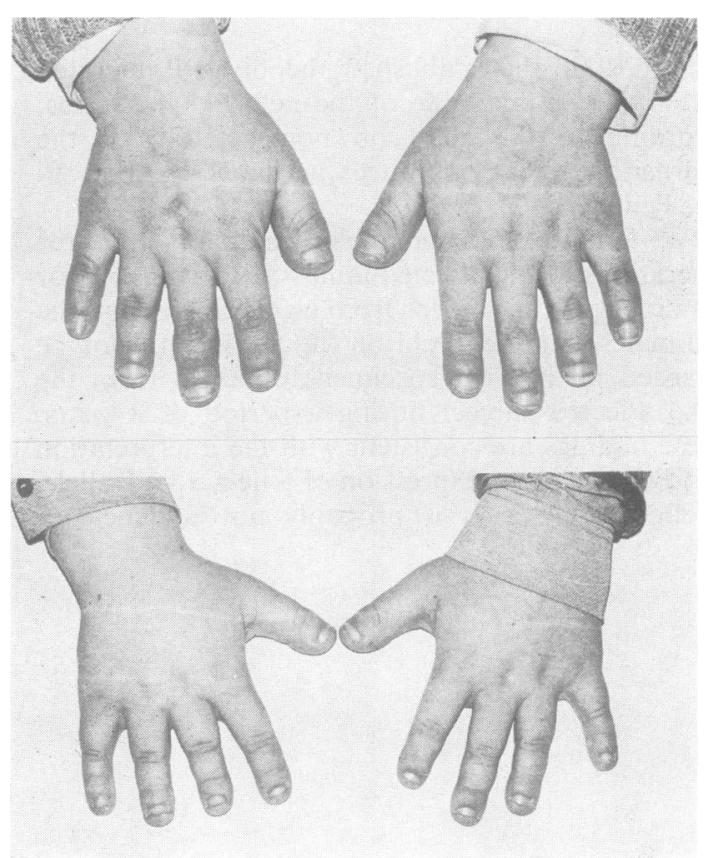

FIG 1 Clinical photograph showing the stubby hands of sister (top) and brother (bottom). 


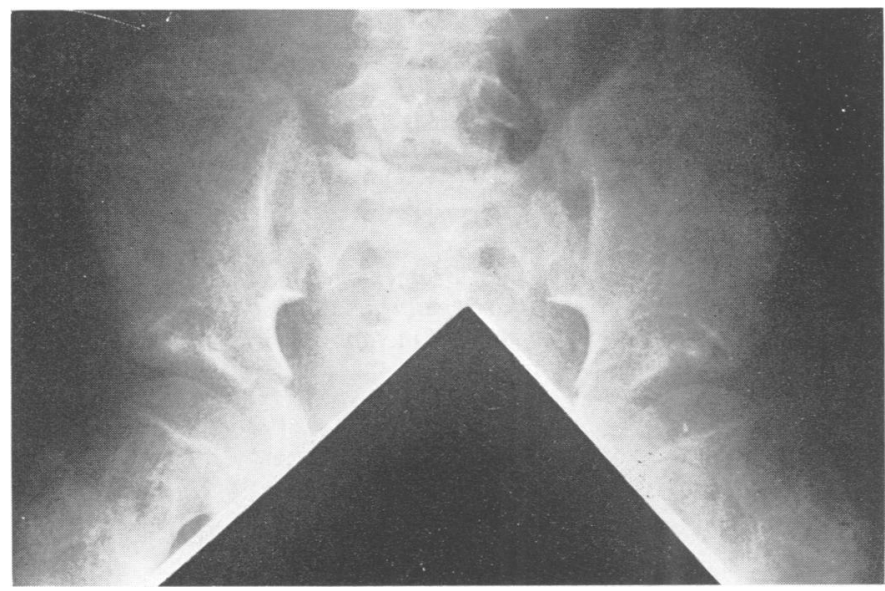

FIG 2 Sister aged 91 years, irregular metaphyseal appearance at the neck of femur and acetabulum.

TABLE Clinical measurements

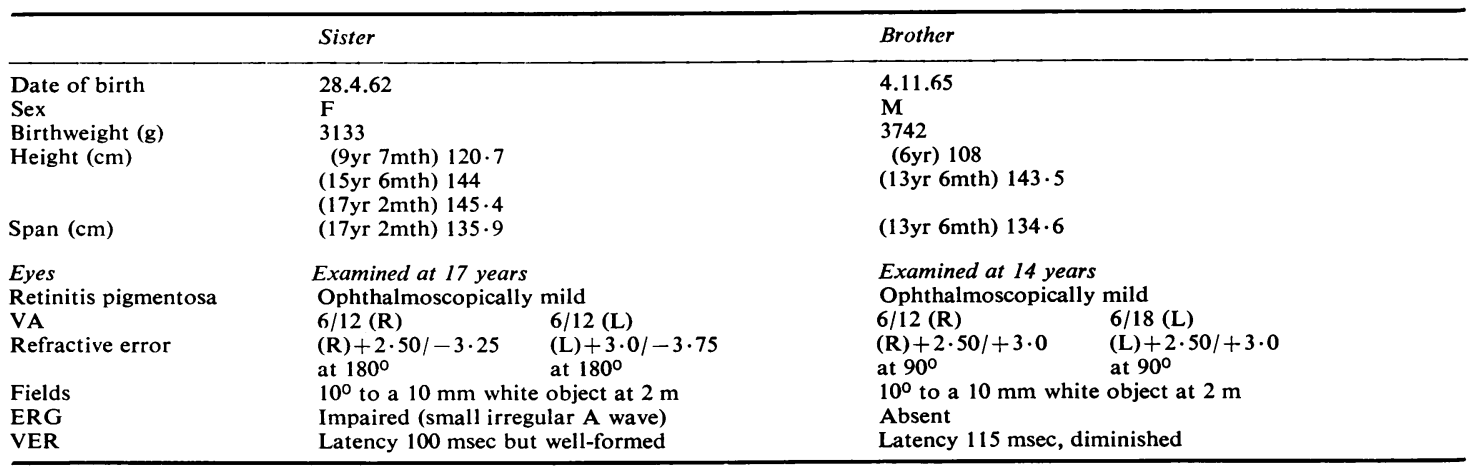

no reports of difficulty until the age of $3 \frac{1}{4}$ years when he was slow in walking and the parents sought orthopaedic advice. No radiological abnormality was reported at this time. At the age of 5 years he too developed a squint and at the age of 6 years, following further examination of his sister, was also diagnosed as having achondroplasia (his height at this time was on the 10th centile and has remained there). His radiological changes were the more severe of the two and clearly indicated a metaphyseal chondrodysplasia (fig 3). By the age of 12 years he was having the same visual problems as his sister and mild changes of retinitis pigmentosa were noted. By 14 years he also had a severely restricted field of vision ( $10^{\circ}$ or less). It is interesting that both children also showed very similar refractive errors (see table, where ERG and VER results are also recorded). Like his sister he had no skeletal problems.

Neither child has had any neurological defect, apart from retinal, and the IQs are within the normal range (sister 91 and brother 82). There has never been evidence of any other systemic defects such as of the pancreas, intestine, blood cells, or immune system. At the ages of 10 and 7 years, respectively, routine blood biochemistry was normal except for raised alkaline phosphatases. Further blood tests have not been done. Urinary mucopolysaccharides were and still are normal, and there is no abnormality in urinary amino-acids.

Both parents are known to be normal both clinically and radiologically. The family history was negative in regard to all aspects of the syndrome, there being no apparent disorder among the four grandparents (two still living), 16 uncles and aunts, or 41 first cousins. The parents are not known to be consanguineous, but they were born in the same small village in Cumbria, north-west England.

\section{$X$-RAY FINDINGS}

At the age of 10 years in the sister and 6 years in the brother the skull and spine were normal. There was some shortening of long bones but the principal 


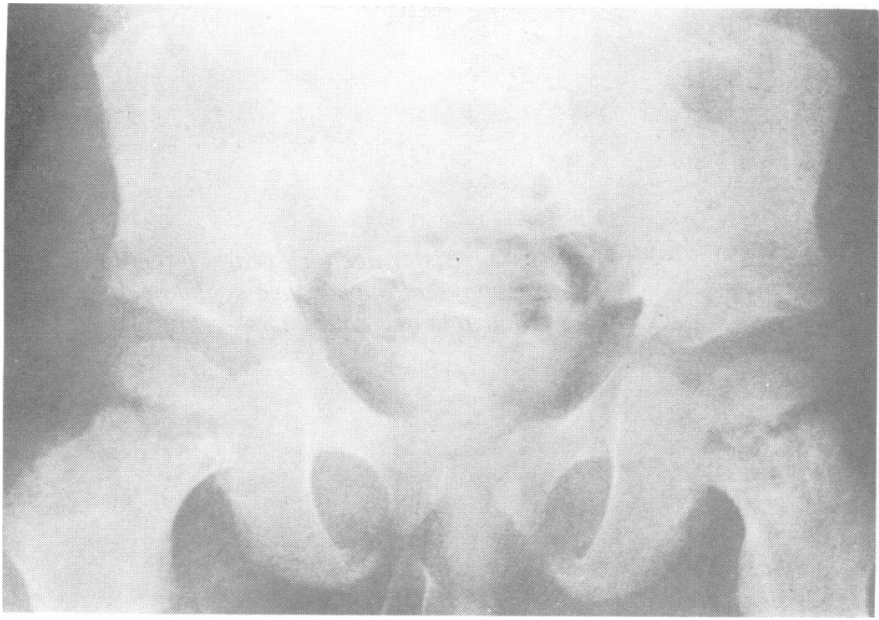

FIG 3 Brother aged 4 years 10 months, with irregular areas of sclerotic bone and $\overrightarrow{0}$ cupping of metaphyses with cyst-like formation.

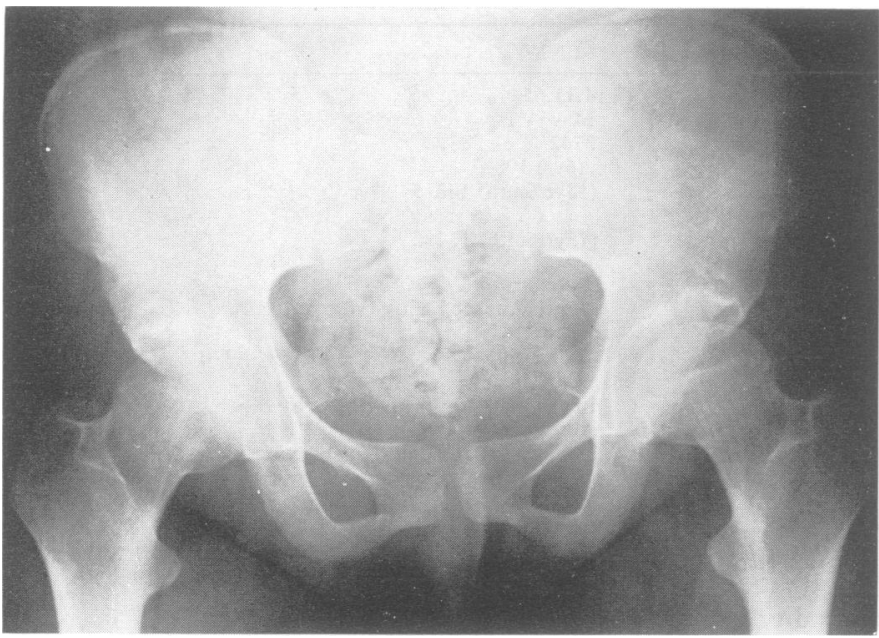

FIG 4 Sister aged 17 years 2 months with normal hip $x$-ray.

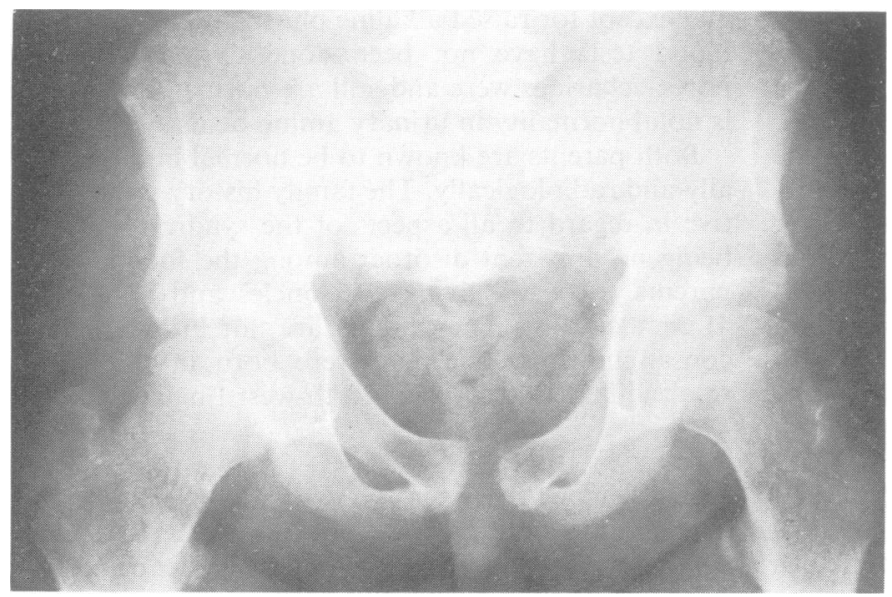

FIG 5 Brother aged 14 years 5 months with an almost normal hip $x$-ray. 

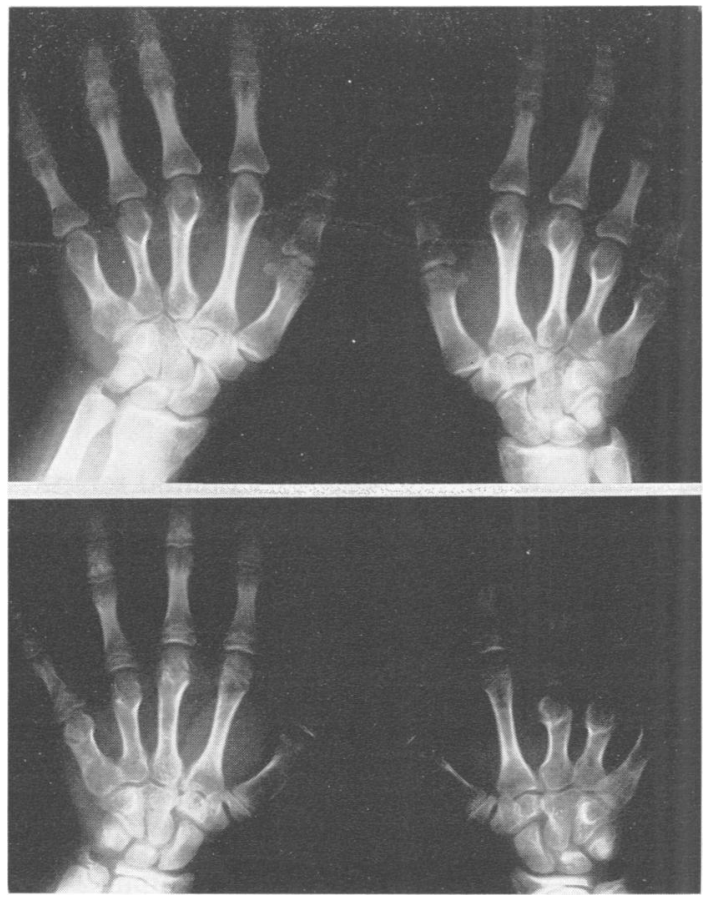

FIG 6 (Top) sister aged 17 years with short metacarpals (except the second) and terminal phalanges. (Bottom) brother aged 14 years, similar.

findings were in the metaphyseal regions, particularly of the upper femoral metaphysis (figs 2, 3), though recent $x$-rays showed the lesions had healed (figs 4, 5). Similar rather lesser changes were seen at the knee, ankle, and wrist. The hands showed marked shortening of some metacarpals and also terminal phalanges, with a more normal length of the proximal and middle phalanges (figs 1,6 ).

\section{Discussion}

The association of retinitis pigmentosa with yet another systemic disease emphasises that the eye disease is not a single entity. This is already well accepted, if only because it can be inherited as an autosomal dominant, recessive, or $\mathrm{X}$ linked recessive.
Both children were of short stature but not markedly so (the sister on the 3 rd centile and the brother on the 10th), this being the result of shortness of the limbs. The upper-lower segment ratio was 1.04 in the girl and 1.07 in the boy. The span was also reduced (between 8 and $10 \mathrm{~cm}$ less than the height). The association of metaphyseal chondrodysplasia and brachydactyly with retinitis pigmentosa has not previously been described, but the metaphyseal lesion itself was non-specific, although clearly dissimilar from types Jansen, Schmid, McKusick, and Peña. It was most like that associated with congenital pancreatic insufficiency and neutropenia. ${ }^{5}{ }^{6}$ However, these children have never had any additional systemic problems. They must for the moment be included among Spranger's type III 'metaphyseal chondrodysplasias with multi-system defects', ${ }^{7}$ and in this instance the disorder is presumably of autosomal recessive inheritance.

It is attractive to think that an enzyme defect in bone may be more easily identified than in the retina, to incriminate another common metabolic pathway, as was done in the case of Refsum syndrome. ${ }^{8}$

\section{References}

1 Duke-Elder S, Dobree JH. Diseases of retina. System of ophthalmology. vol X. London: Kimpton, 1967:609-15.

2 Refsum S. Heredopathia atactica polyneuritiformis. $J$ Nerv Ment Dis 1952;116:1046-64.

3 Kornzweig AL, Bassen FA. Retinitis pigmentosa, acanthrocytosis and heredo-degenerative neuromuscular disease. Arch Ophthalmol 1957;58:183-7.

4 Krill AE, Archer DB. Krillo hereditary retinal and chorondal diseases. Clinical characteristics. vol 2. New York: Harper and Row, 1977:529.

5 Sutcliffe J, Stanley P. Metaphyseal chondrodysplasias. Intrinsic disease of bones. Progress in pediatric radiology. vol 4. Basel: Karger, 1973:250-69.

6 Ray HC, Dorst JP. Cartilage-hair hypoplasia. Intrinsic diseases of bones. Basel: Karger, 1973:270,98.

7 Spranger JW. Metaphyseal chondrodysplasias. Birth Defects 1976;XII(No 6):33-46.

8 Kahlke W, Wagener H. Conversion of H3-phytol to phytanic acid and its incorporation into plasma lipid fractions in heredopathia atactica polyneuritiformis. Metabolism 1963;15:687-93.

Requests for reprints to $\mathrm{Dr} R$ Wynne-Davies, Department of Orthopaedic Surgery (Clinical Genetics), University of Edinburgh, 24 Buccleuch Place, Edinburgh EH8 9LN. 